\title{
Diet composition and neighboring prey community of the Phuping newt (Tylototriton uyenoi) in Maesa-Kogma Biosphere Reserve, Chiang Mai Province, northern Thailand
}

\author{
THANSUDA DOWWIANGKAN ${ }^{1,2, v}$, YODCHAIY CHUAYNKERN ${ }^{3, v v}$, PONGRAT DUMRONGROJWATTANA, ${ }^{4, v v v, ~}$

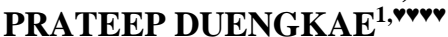 \\ ${ }^{1}$ Department of Forest Biology, Faculty of Forestry, Kasetsart University. 50 Ngamwongwan Rd., Chatuchak, Bangkok 10900, Thailand. \\ Tel.: +66-2579-0176, Fax.: +66-2942-8107, `email: red_club72@hotmail.com, thansuda.do@ku.th; ^vvvemail: prateep.du@ku.ac.th \\ ${ }^{2}$ Wildlife Research Division, Wildlife Conservation Office, Department of National Parks, Wildlife and Plant Conservation. Chatuchak, Bangkok 10900, \\ Thailand \\ ${ }^{3}$ Department of Biology, Faculty of Science, Khon Kaen University. Mueang Khon Kaen, Khon Kaen 40002, Thailand. \\ Tel./fax.: +66-8-6005-2507, ^vemail: yodchaiy@kku.ac.th \\ ${ }^{4}$ Department of Biology, Faculty of Science, Burapha University. Mueang Chon Buri, Chon Buri 20131, Thailand \\ Tel./fax.: +66-3810-2109, ^vvemail: pongrat@buu.ac.th
}

Manuscript received: 5 July 2020. Revision accepted: 8 September 2020.

\begin{abstract}
Dowwiangkan T, Chuaynkern Y, Dumrongrojwattana P, Duengkae P. 2020. Diet composition and neighboring prey community of the Phuping newt (Tylototriton uyenoi) in Maesa-Kogma Biosphere Reserve, Chiang Mai Province, northern Thailand. Biodiversitas 21: 4515-4523. The present work reports the comparison of fecal pellet prey composition of Tylototriton uyenoi from Maesa-Kogma Biosphere Reserve (Chiang Mai Province, northern Thailand) based on an analysis of its fecal pellets. Males of T. uyenoi consumed more diverse prey than those of females (53 groups of prey versus 14 groups). The analysis reveals a diverse diet of Arthropoda (Insecta, Arachnida, Diplopoda, Chilopoda, and Malacostraca), Mollusca (Gastropoda), Chordata, and conspecific eggs. Partial remnants of plant materials were also found in the pellets. The percentage frequency of prey occurrence was higher in Formicidae (21.34), Lymnaeidae (17.39), unknown snails (10.67), and Blattidae (9.881). The percentage of the relative number of preys was higher in Lymnaeidae (41.02) and Formicidae (17.17). The volumetric prey percentage was higher in Lymnaeidae (30.78), Paradoxosomatidae (19.14), and unknown snails (12.71). The index of relative importance was higher in Lymnaeidae (1,248.62), Formicidae (376.972), unknown snails (188.275), and Paradoxosomatidae (166.433). The percentage of IRI was higher in Lymnaeidae (57.128) and Formicidae (17.248). The Spearman rank coefficient (95\% confidence interval test) showed a significant positive correlation $(p<0.05)$ between prey volume and number and SVL.
\end{abstract}

Keywords: Ecology, fecal pellet analysis, prey items, Salamandridae

\section{INTRODUCTION}

The Phuping newt Tylototriton uyenoi, also known as the Asian newt, is the urodele amphibian of the family Salamandridae knew from Thailand (Frost 2020). It was described as a new species in 2013 (Nishikawa et al. 2013). Distribution of the genus Tylototriton ranges from the high elevations of the eastern Himalayas to central China and mainland Southeast Asia (Shen et al. 2012; Qian et al. 2017). This includes the lower montane evergreen forest in the Maesa-Kogma Biosphere Reserve in Chiang Mai Province, Thailand. Major populations of T. uyenoi can be found in cold climate mountains at elevations of $1,000 \mathrm{~m}$ above sea level or more (Pomchote et al. 2008; Nishikawa et al. 2013; Hernandez 2016; Hernandez 2017; Hernandez et al. 2019). The newts live in clearwater streams along the least disturbed mountains and their presence can indicate the health of local montane forest ecosystems (Marod and Kutintara 2009). In addition, they transfer energy from aquatic to land habitats when they metamorphose into a terrestrial stage (Duellman and Trueb 1994; Le et al. 2018). The Phuping newt is currently threatened by extensive deforestation for agricultural activity, shifting cultivation, pollution from human settlement, and overharvesting for the international pet trade (Pattanavibool and Dearden 2002; Chuaynkern and Duengkae 2014; Rowley et al. 2016). Climate change also presents problems in tropical areas as increased temperature could decrease newt populations by changing their life cycle and breeding sites (Bickford et al. 2010). Accordingly, the conservation status of Tylototriton populations in Thailand was re-evaluated and is currently listed as a protected by Thai law: The Wild Animal Reservation and Protection Act B.E. 2535 due to taxonomic change (Ministry of Natural Resources and Environmental 2017).

Tylototriton foraging and diet were reported for Tylototriton himalayanus (formerly Tylototriton verrucosus) in Indian Darjeeling (Kuzmin et al. 1994; Dusgupta 1996) and Manipur state (Devi 2005), India (Devi 2005), as well as for Tylototriton podichthys in Xiengkhouang Province, Laos (Phimmachak et al. 2015). According to Pomchote et al. (2008), larvae of $T$. verrucosus feed mainly on small crustaceans (the water fleas Moina macrocapa) and also showed cannibalistic 
behaviors among larval siblings of different sizes. The adult newts consume small invertebrates (bloodworms Chironomus sp., mealworms Tenebrio molitor, crickets Acheta sp.) and vertebrates. The Tytlototriton newt's natural feeding and dietary selection patterns in Thailand are poorly known. Based on analysis of fecal pellets, Ponpituk (2014) found that adults T. uyenoi in Doi SuthepPui National Park (Chiang Mai Province, Thailand) consumed diverse arthropods (Arachnida, Diplopoda, Insecta) and mollusks (Bivalvia). Dowwiangkan et al. (2016) found that adults T. uyenoi from Chiang Mai Province (the Royal Agricultural Station Ang Khang and Maesa-Kogma Biosphere Reserve) also consumed arthropods (classes Arachnida, Diplopoda, Insecta) and mollusks (class Bivalvia). As the diet ecology information of the newts in their natural habitat is still far from fully known, our study aims to investigate the food items based on the fecal pellet analysis and food selection of $T$. uyenoi from Maesa-Kogma Biosphere Reserve, northern Thailand. The results of this study add information on dietary of the species and can improve understanding about Tylototriton newts feeding ecology and the role that they play in their ecosystems.

\section{MATERIALS AND METHODS}

\section{Study area}

Maesa-Kogma Biosphere Reserve (Figure 1) is located in Chiang Mai Province, northern Thailand. The area occupies 57,366 hectares, which is mostly part of Doi Suthep-Pui National Park. Field surveys were performed at a 16-hectare $\left(160,000 \mathrm{~m}^{2}\right)$ permanent plot (Figure 1B) at $1,332 \mathrm{~m}$ above sea level in the Maesa-Kogma Biosphere Reserve at the coordinates of $18^{\circ} 48^{\prime} 45.7^{\prime \prime} \mathrm{N}, 98^{\circ} 54^{\prime} 7.7^{\prime \prime} \mathrm{E}$. Vegetation type is lower montane forest and the area is the type locality of T. uyenoi (Nishikawa et al. 2013). Research and specimen collection were performed under the permission of the Department of National Parks, Wildlife and Plant Conservation (Permission number DNP 0907.4/9819).

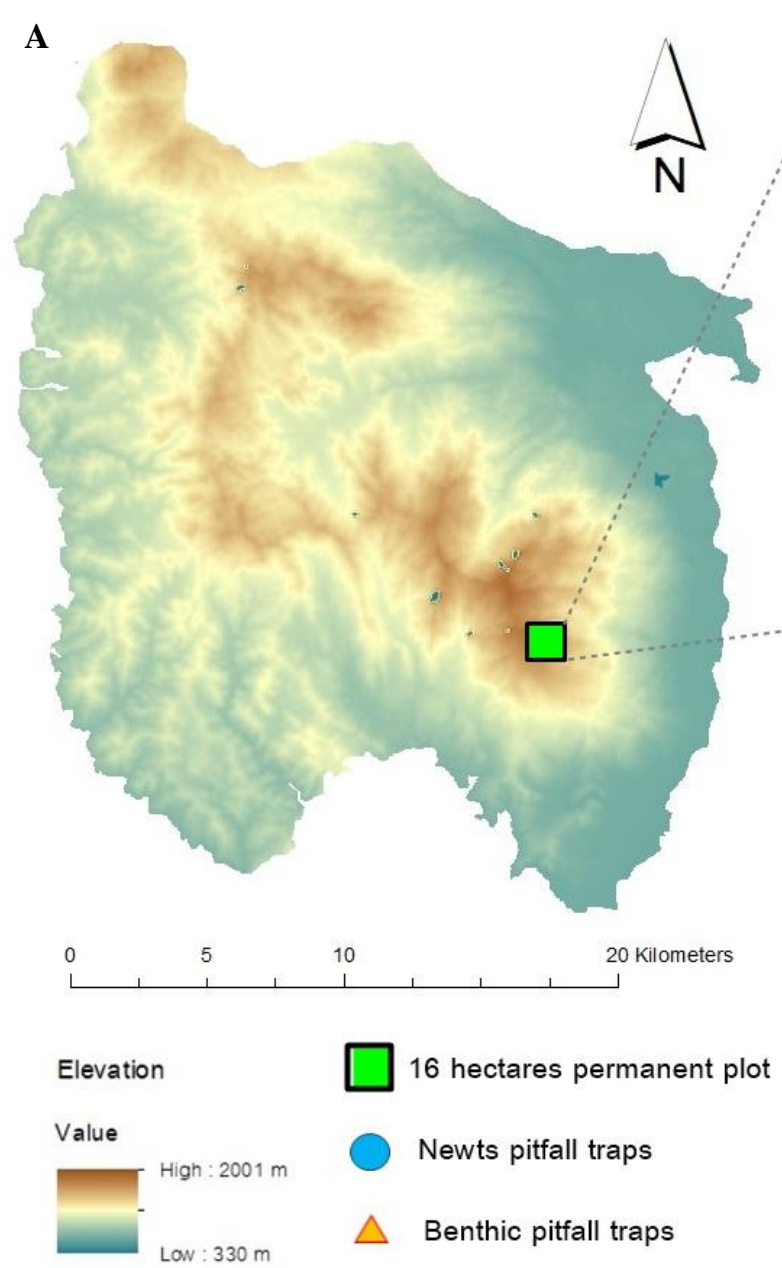

B

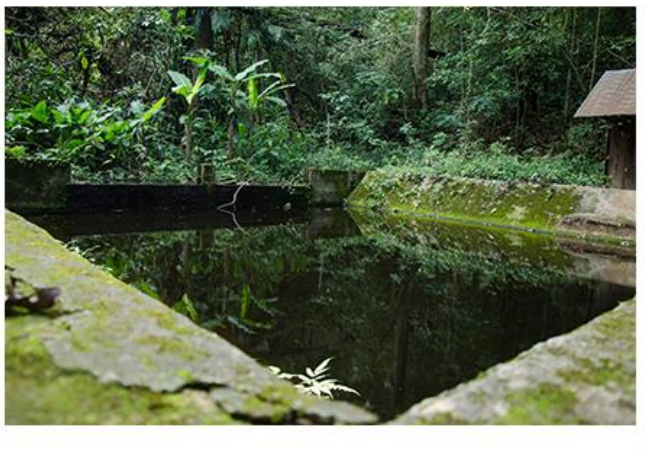

Figure 1. Study site, Maesa-Kogma Biosphere Reserve, Chiang Mai Province, Thailand 


\section{Sampling and fecal pellet collection}

For trapping T. uyenoi, we used 49 plastic tanks $30 \mathrm{~cm}$ in diameter and $40 \mathrm{~cm}$ deep-set as pitfall traps. These traps were systematically embedded at 50-m intervals throughout the 16-hectare permanent plot (Figure 1.B). Sampling was conducted monthly (3 nights per month) from March 2017 through September 2018. Captured newts were placed in $16 \times 26$ inch transparent plastic bags (one per newt) and kept overnight. On the following morning, we collected fecal pellets from each plastic bag and preserved them in $70 \%$ ethanol for identifying food items in the laboratory (Chuaynkern et al. 2009; Thongproh et al. 2019). After collecting feces, we marked the newts by injecting colored, visible implant elastomer (VIE) tags (Northwest Marine Technology Inc., Shaw Island, WA) below the skin with a $0.3-\mathrm{ml}$ insulin syringe. We marked the newts at four points 5-10 $\mathrm{mm}$ behind the cloaca according to Lunghi et al. (2014) and Dowwiangkan et al. (2018). The captured newts were weighed using digital scales. We measured six morphological characteristics using an analog vernier caliper. Measurements were as follow: SVL (snout to vent length) measured from tip of snout to anterior tip of the vent, TL (tail length) measured from anterior tip of the vent to the tip of the tail, TTL (total length) measured from tip of snout to tip of the tail, MW (mouth width) measured distance between corner of the mouth, HW (head width) measured between position of maximum head width. We identified the sex of the newts by the cloacal shape. Finally, the newts were released to their natural habitat.

For investigating the availability of terrestrial foods in their natural habitat, we used the benthic pitfall trapping technique (Woodcock 2005). The smaller benthic pitfall traps were 49 cylindrical plastic containers $10 \mathrm{~cm}$ in diameter and $15 \mathrm{~cm}$ deep-set alongside the newt pitfall traps. Each benthic trap was filled with $50 \%$ ethanol at a volume $1 / 3$ of the depth of the trap. We also investigated aquatic food in artificial pond located in the16-hectare $\left(160,000 \mathrm{~m}^{2}\right)$ permanent plot (Figure 1.C). by using 30x30 $\mathrm{cm}$ iron net boxes (mesh size $1 \times 1 \mathrm{~mm}$ ) as in Dusgupta (1996). A total of 16 boxes were placed on the bottom of the pond near pond edges and in the middle of the pond. All captured aquatic animals were preserved in $70 \%$ ethanol.

\section{Food item analysis}

Fecal pellet contents and terrestrial and aquatic communities were identified using a stereomicroscope at the Faculty of Forestry at Kasetsart University, Bangkok. Prey fragments found in pellets and terrestrial and aquatic organisms found in traps were identified via comparison with relevant taxonomic references (Chuensri 1974; Monzon et al. 1993; Naiyanetr 1997; Triplehorn and Johnson 2005; Inmadon et al. 2011; Ponpituk 2014). Items were also photographed and measured using a digital caliper.

Index of Relative Importance (IRI) for each prey type in newt diet was calculated using the formula IRI $=\% \mathrm{Fi}$ $(\% \mathrm{Ni}+\% \mathrm{Vi})$, where $\% \mathrm{Ni}$ is the percentage number of prey type $\mathrm{i}$ (relative to total number of prey), and $\% \mathrm{Vi}$ and $\% \mathrm{Fi}$ are the percentage volume and the percentage frequency of occurrence of prey type, respectively (Pinkas et al. 1971). We also converted the IRI as percentage of the total index (followed Oliveira et al. 2007), \% IRI $=($ IRR $/ \Sigma$ IRI $) \times 100$. Correlation between volume of prey consumed and body size was tested using Spearman's rank correlation. The mean with $95 \%$ confidence intervals was used to evaluate the relationship between body size (MW, HW, SVL, TTL, weight) and prey volume in each sex (Griffiths 1986).

\section{RESULTS AND DISCUSSION}

\section{Results}

We collected 253 fecal pellets from 295 trapped individuals of T. uyenoi (209 males and 86 females) at 440 capture times. Food items were found in 220 pellets but not in the remaining 33 pellets. Based on analysis of the 220 fecal pellets containing identifiable food, we identified 626 individual food items that were distributed in three phyla: Arthropoda, Mollusca, and eggs of T. uyenoi (Table 1). Food items could be divided further into 57 taxonomic categories, with most categories coming from taxa that occupied the terrestrial habitat $(91.22 \%)$ and only $8.77 \%$ of aquatic taxa. Males of $T$. uyenoi consumed more diverse prey than those of females (53 groups of prey versus 14 groups). The males consumed mainly on arthropods (43 groups), mollusks (9 groups), and eggs of T. uyenoi. Percentage frequency of occurrence $(\% \mathrm{~F})$ was higher in Formicidae (19.763) and Lymnaeidae (17.391). Percentage relative number of individuals of prey $(\% \mathrm{~N})$ was higher in Lymnaeidae (41.018) and Formicidae (16.375). Percentage volumetric $(\% \mathrm{~V})$ was higher in Ixodidae $(0.234)$ and Histeridae (0.096). The index of relative importance (IRI) was higher in Paradoxosomatidae $(2,073.704)$ and Potamidae (2,012.536). The percentage of IRI (\%IRI) was higher in Paradoxosomatidae (94.88) and Potamidae (92.08). Like the males, the females consumed mainly on arthropods (11 groups) and mollusks (3 groups). Percentage frequency of occurrence was higher in Paradoxosomatidae (1.976) and Pseudoscorpiones (1.86) and unknown snails (1.186). Percentage relative number of individuals of prey was higher in Paradoxosomatidae (0.795) and unknown snails (0.795) and Isoptera (0.636). Percentage volumetric was higher in Paradoxosomatidae (4.217) and unknown snails (1.482). The index of relative importance (IRI) was higher in Paradoxosomatidae (2.536), Potamidae (2.481), and unknown snails (1.92). The percentage of IRI was higher in Paradoxosomatidae (0.116) and Potamidae (0.113).

In both sexes, T. uyenoi were found throughout the year (except in March 2018 that was not surveyed), most often during the rainy season and least often in the dry season. In 2017, T. uyenoi were captured in all months from March through December (Figure 2). Similarly, most of the fecal pellets were obtained during the rainy season, especially in May through August. For 2018, the number of captured newts and collected fecal pellets were similar to those of the previous year.

Analysis of fecal pellet contents of males and females showed that $T$. uyenoi consumed diverse arthropods (46 groups), mollusks (10 groups), and eggs of T. uyenoi. The newts ate five classes of Arthropoda: Insecta (12 orders), 
Arachnida (4 orders), Diplopoda (2 orders), Chilopoda (1 order), and Malacostraca (1 order). For Mollusca, T. uyenoi ate 1 class, Gastropoda ( 3 orders). In Chordata, T. uyenoi ate amphibian eggs. Prey type frequency was higher in Arthropoda (70.75\%) and Mollusca (Gastropoda: $36.36 \%$ ). However, Gastropoda represented the highest proportion in number and volume of food items. We also found plant materials (e.g., seed, leaf fragments, mosses) and pebbles, but those were excluded from our analysis. Percentage frequency of occurrence was higher in Formicidae (21.34), Lymnaeidae (17.39), unknown snails (10.67), and Blattidae (9.881). Percentage relative number of individuals of prey was higher in Lymnaeidae (41.02) and Formicidae (17.17). Percentage volumetric was higher in Lymnaeidae (30.78), Paradoxosomatidae (19.14), and unknown snails (12.71). The index of relative importance was higher in Lymnaeidae (1,248.62), Formicidae (376.972), unknown snails (188.275), and Paradoxosomatidae (166.433). The percentage of IRI was higher in Lymnaeidae (57.128) and Formicidae (17.248).

The Spearman rank coefficient $(95 \%$ confidence interval test) showed a significant positive correlation $\left(\mathrm{r}_{\mathrm{s}}\right.$ [rho] $=-0.1270, p=0.0443(p<0.05))$ between prey volume and SVL (Figure 3$)$. The prey volume and mouth $\left(\mathrm{r}_{\mathrm{s}}(\mathrm{rho})=\right.$ $-0.0482, p=0.4454)$, prey volume and weight $\left(\mathrm{r}_{\mathrm{s}}\right.$ [rho] = $0.0711, p=0.2595)$, and prey volume and total length $\left(r_{\mathrm{s}}\right.$ [rho] $=-0.0081, p=0.1979)$ had negative correlation $(p<0.05)$.

Number of prey individuals and SVL had a significant positive correlation $\left(\mathrm{r}_{\mathrm{s}}(\mathrm{rho})=-0.1563, p=0.0128, p<0.05\right)$ while as number of prey volume and mouth $\left(\mathrm{r}_{\mathrm{s}}\right.$ (rho) = $0.0713, p=0.2583)$, number of prey volume and weight $\left(\mathrm{r}_{\mathrm{s}}\right.$ (rho) $=-0.0037, p=0.9536)$, and number of prey volume and total length (rs (rho) $=-0.1082, p=0.0858$ ) had negative correlation $(p<0.05)$ (Figure 4$)$.
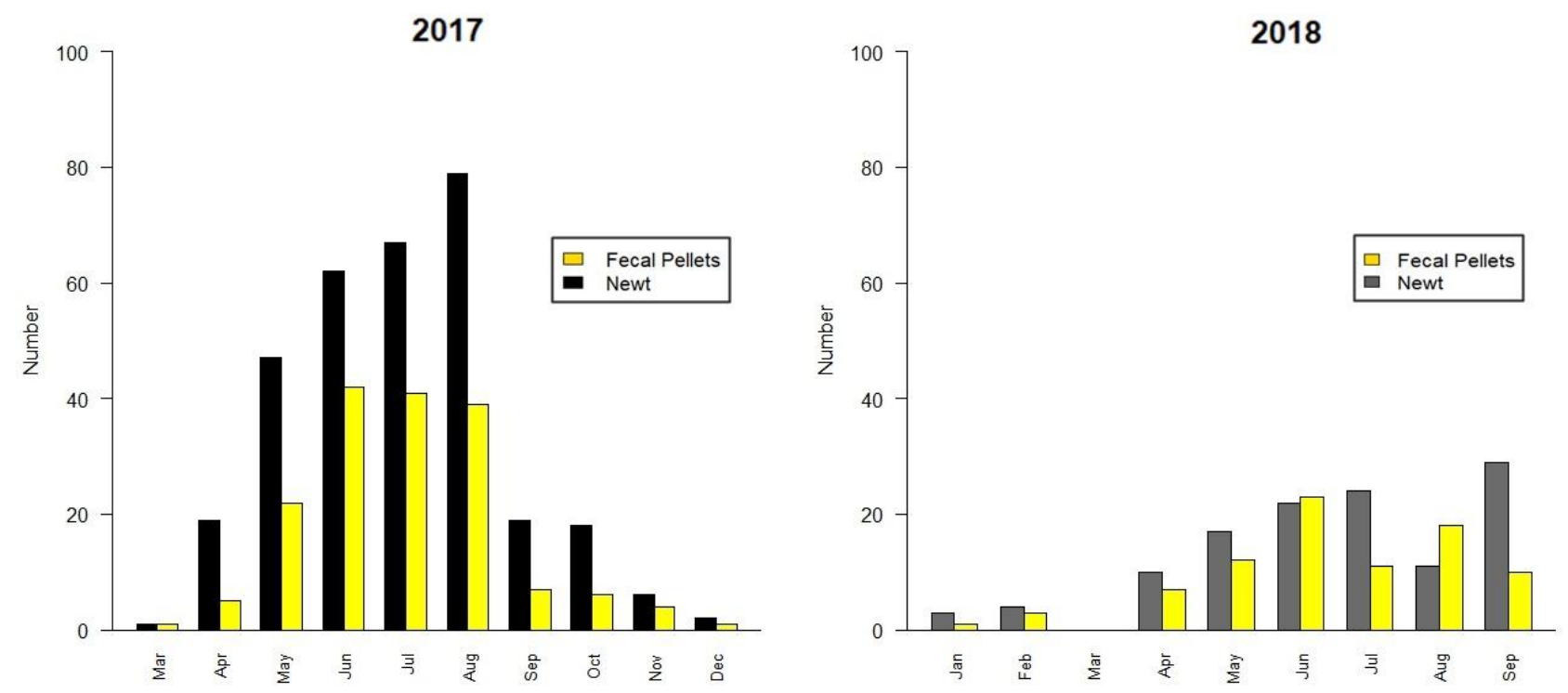

Figure 2. Captured newts and fecal pellets collected each month during the study period, March 2017 through September 2018. Note that March was not surveyed in 2018.

Table 1. Diet composition of Tylototriton uyenoi collected from Maesa-Kogma Biosphere Reserve, Chiang Mai Province, Thailand

\begin{tabular}{|c|c|c|c|c|c|c|c|c|}
\hline Phylum & Class & Prey items & Nich & $\% \mathbf{F}$ & $\% \mathbf{N}$ & $\% \mathrm{~V}$ & IRI & $\%$ IRI \\
\hline \multirow[t]{11}{*}{ Arthropoda } & Insecta & $\begin{array}{l}\text { Order Archeognatha } \\
\text { Order Odonata }\end{array}$ & Ter & 0.345 & 0.159 & 0.002 & 0.064 & 0.003 \\
\hline & & Suborder Anisoptera & $\mathrm{Aq}$ & 1.976 & 0.795 & 3.661 & 8.807 & 0.403 \\
\hline & & Suborder Zygoptera & $\mathrm{Aq}$ & 3.162 & 1.272 & 0.346 & 5.116 & 0.234 \\
\hline & & $* * * N y m p h$ & $\mathrm{Aq}$ & 0.395 & 0.159 & 0.053 & 0.084 & 0.004 \\
\hline & & Order Orthoptera & & & & & & \\
\hline & & Family Gryllidae & Ter & 3.162 & 1.272 & 1.453 & 8.618 & 0.394 \\
\hline & & Family Acrididae & Ter & 0.791 & 0.318 & 0.216 & 0.422 & 0.019 \\
\hline & & Family Tettigoniidae & Ter & 0.791 & 0.318 & 0.340 & 0.520 & 0.024 \\
\hline & & Order Blattodea & & & & & & \\
\hline & & Family Corydiidae & Ter & 0.791 & 0.318 & 0.535 & 0.675 & 0.031 \\
\hline & & Family Blattidae & Ter & 9.881 & 3.975 & 2.034 & 59.370 & 2.716 \\
\hline
\end{tabular}




\begin{tabular}{|c|c|c|c|c|c|c|c|c|}
\hline & & Order Isoptera & Ter & 2.767 & 2.226 & 0.127 & 6.510 & 0.298 \\
\hline & & Order Dermaptera & & & & & & \\
\hline & & Family Cacinophoridae & Ter & 5.138 & 2.067 & 6.573 & 44.396 & 2.031 \\
\hline & & Family Forficulidae & Ter & 0.395 & 0.159 & 0.557 & 0.283 & 0.013 \\
\hline & & Order Hemiptera & & & & & & \\
\hline & & Family Lygaeidae & Ter & 0.395 & 0.159 & 0.604 & 0.301 & 0.014 \\
\hline & & ***Nymph & Ter & 0.395 & 0.159 & 0.005 & 0.065 & 0.003 \\
\hline & & Order Homoptera & & & & & & \\
\hline & & $\begin{array}{l}\text { Family Delphacidae } \\
\text { Order Coleoptera }\end{array}$ & Ter & 0.395 & 0.159 & 0.155 & 0.124 & 0.006 \\
\hline & & Family Coccinellidae & Ter & 0.395 & 0.159 & 0.194 & 0.140 & 0.006 \\
\hline & & Family Curculionidae & Ter & 3.162 & 1.431 & 1.504 & 9.279 & 0.425 \\
\hline & & Family Attelabidae & Ter & 0.395 & 0.159 & 0.157 & 0.125 & 0.006 \\
\hline & & Family Staphylinidae & Ter & 0.395 & 0.159 & 0.064 & 0.088 & 0.004 \\
\hline & & Family Elateridae & Ter & 1.976 & 0.795 & 0.879 & 3.308 & 0.151 \\
\hline & & Family Buprestidae & Ter & 0.791 & 0.318 & 0.107 & 0.336 & 0.015 \\
\hline & & Family Tenebrionidae & Ter & 1.186 & 0.477 & 0.344 & 0.974 & 0.045 \\
\hline & & Family Cerambycidae & Ter & 0.395 & 0.159 & 0.374 & 0.211 & 0.010 \\
\hline & & Family Endomychidae & Ter & 0.395 & 0.159 & 0.220 & 0.150 & 0.007 \\
\hline & & Family Histeridae & Ter & 0.395 & 0.477 & 0.096 & 0.227 & 0.010 \\
\hline & & Family Trogidae & Ter & 0.395 & 0.159 & 0.054 & 0.084 & 0.004 \\
\hline & & Family Unknown & Ter & 0.395 & 0.159 & 0.197 & 0.141 & 0.006 \\
\hline & & ***Larvae & Ter & 3.557 & 1.431 & 1.830 & 11.601 & 0.531 \\
\hline & & Order Lepidoptera & & & & & & \\
\hline & & Family Psychidae & Ter & 1.581 & 1.749 & 0.464 & 3.498 & 0.160 \\
\hline & & $* * *$ Pupae & Ter & 0.395 & 0.159 & 0.385 & 0.215 & 0.010 \\
\hline & & $* *$ Larvae & Ter & 0.791 & 0.318 & 0.171 & 0.387 & 0.018 \\
\hline & & Order Diptera & Ter & 0.791 & 0.318 & 0.152 & 0.372 & 0.017 \\
\hline & & Family Tachinidae & Ter & 0.395 & 0.159 & 0.084 & 0.096 & 0.004 \\
\hline & & Family Tephritidae & Ter & 0.791 & 0.318 & 0.105 & 0.335 & 0.015 \\
\hline & & $* * *$ Larvae & Ter & 0.791 & 0.318 & 0.152 & 0.372 & 0.017 \\
\hline & & Order Hymenoptera & & & & & & \\
\hline & & Family Formicidae & Ter & 21.340 & 17.170 & 0.492 & 376.972 & 17.248 \\
\hline & & Family Vespidae & Ter & 0.395 & 0.159 & 0.037 & 0.078 & 0.004 \\
\hline & Arachnida & Order Araneae & & & & & & \\
\hline & & Family Salticidae & Ter & 2.372 & 1.113 & 1.732 & 6.747 & 0.309 \\
\hline & & Family Sparassidae & Ter & 0.791 & 0.318 & 0.368 & 0.542 & 0.025 \\
\hline & & Order Opiliones & & & & & & \\
\hline & & Family Sclerosomatidae & Ter & 0.791 & 0.318 & 0.562 & 0.696 & 0.032 \\
\hline & & Order Pseudoscorpiones & Ter & 1.976 & 0.954 & 0.325 & 2.527 & 0.116 \\
\hline & & Order Scopiones & & & & & & \\
\hline & & Family Scorpionidae & Ter & 0.395 & 0.159 & 0.234 & 0.155 & 0.007 \\
\hline & Diplopoda & Order Julida & Ter & 0.791 & 0.318 & 0.856 & 0.928 & 0.042 \\
\hline & & Order Polydesmida & & & & & & \\
\hline & & Family Paradoxosomatidae & Ter & 7.51 & 3.021 & 19.14 & 166.433 & 7.615 \\
\hline & Chilopoda & Order Scolopendromorpha & Ter & 1.581 & 0.636 & 0.642 & 2.021 & 0.092 \\
\hline & Malacostraca & Order Decapoda & & & & & & \\
\hline & & Family Potamoidea & Ter & 2.372 & 0.954 & 5.108 & 14.376 & 0.658 \\
\hline Mollusca & Gastropoda & Order Mesogastropoda & & & & & & \\
\hline & & Family Lymnaeidae & $\mathrm{Aq}$ & 17.390 & 41.020 & 30.780 & 1248.620 & 57.128 \\
\hline & & Family Cyclophoridae & Ter & 0.791 & 0.318 & 0.044 & 0.286 & 0.013 \\
\hline & & Order Stylommatophora & & & & & & \\
\hline & & Family Camaenidae & Ter & 0.791 & 0.477 & 0.368 & 0.668 & 0.031 \\
\hline & & Family Clausiliidae & Ter & 1.186 & 0.477 & 0.413 & 1.055 & 0.048 \\
\hline & & Family Subulinidae & Ter & 1.581 & 0.795 & 0.649 & 2.283 & 0.104 \\
\hline & & Family Helicarionidae & Ter & 1.976 & 0.795 & 1.338 & 4.216 & 0.193 \\
\hline & & Family Pyramidulidae & $\mathrm{Aq}$ & 1.581 & 0.795 & 0.120 & 1.446 & 0.066 \\
\hline & & Order Architaenioglossa & Ter & 0.791 & 0.477 & 0.368 & 0.668 & 0.031 \\
\hline & & Diplommatinidae & Ter & 0.791 & 0.318 & 0.019 & 0.267 & 0.012 \\
\hline & & Unknown snails & Ter & 10.67 & 4.928 & 12.710 & 188.275 & 8.614 \\
\hline Chordata & Amphibia & Order Urodela & & & & & & \\
\hline & & Family Salamandridae [Eggs] & Ter & 0.395 & 0.318 & 0.014 & 0.131 & 0.006 \\
\hline
\end{tabular}



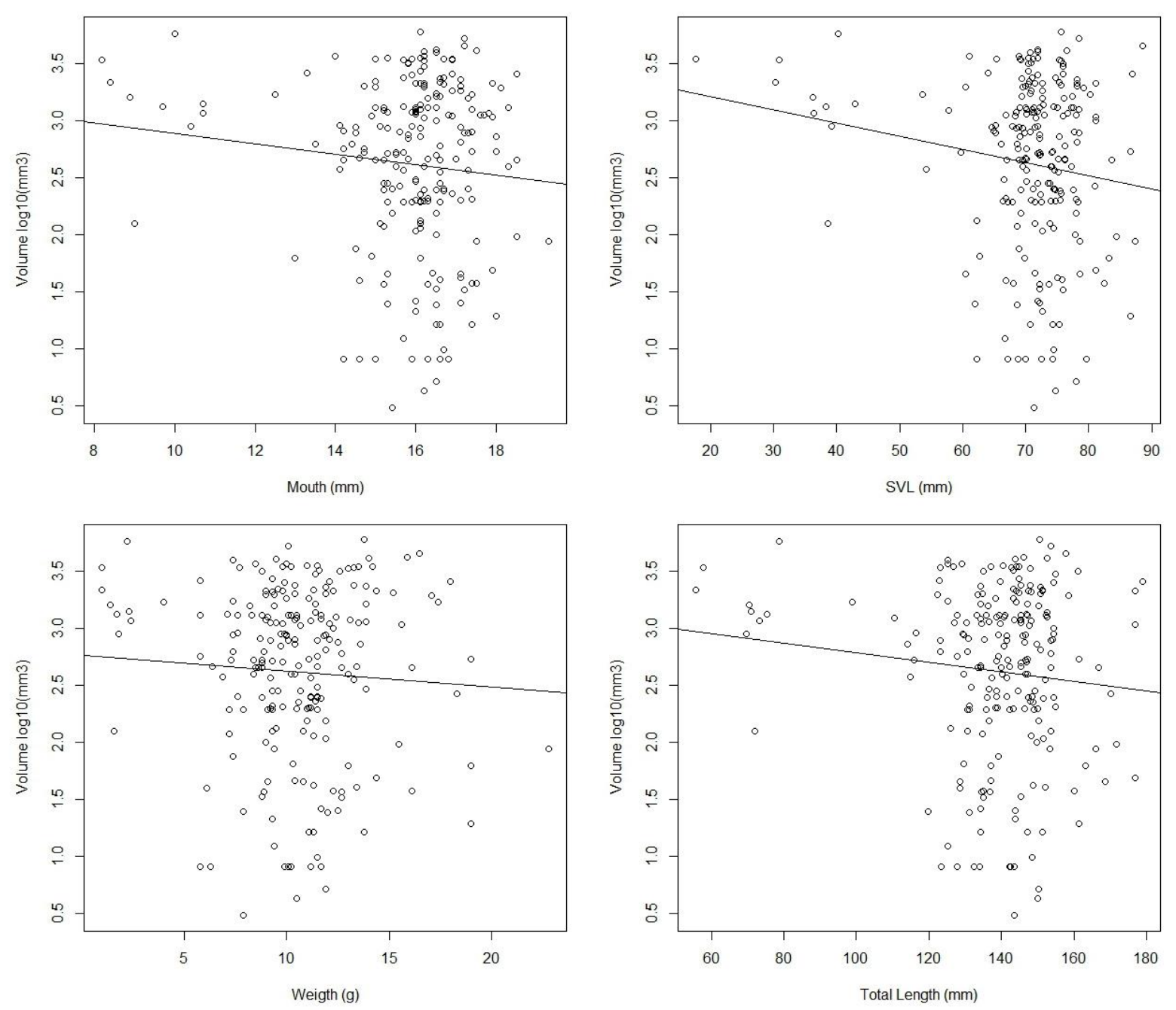

Figure 3. The Spearman rank coefficient ( $95 \%$ confidence interval test) comparison of prey volume versus mouth width, SVL, body weight and total length. A. prey volume versus mouth, B. prey volume versus SVL, C. prey volume versus weight, D. prey volume versus total length. Prey volume and SVL had a significant negative correlation $(\mathrm{p}<0.05)$

\section{Discussion}

Dowwiangkan et al. (2016) analyzed 67 fecal pellets obtained from 102 individuals of $T$. uyenoi which were collected in two periods (January-December 2013 and April-September 2015) from the Royal Agricultural Station Ang Khang (55 fecal pellets from 81 individuals) and Maesa-Kogma Biosphere Reserve (12 fecal pellets from 21 individuals), Chiang Mai Province, northern Thailand. The diets consisted of two phyla: Arthropoda (classes Arachnida, Diplopoda, Insecta) and Mollusca (class Bivalvia). Unlike Dowwiangkan et al. (2016), we did not observe four families of the class Insecta in fecal pellets: Carabidae (order Coleoptera), Chelisochidae (order Dermaptera), and Gryllacrididae (order Orthoptera). Our findings also included one more phylum, Chordata (class Amphibia: Urodela/Salamandridae). We found parts of newts' eggs in the fecal pellets of the male. Conspecific oophagy is also seen in T. verrucosus from India (Kuzmin et al. 1994; Dasgupta 1996; Lucy et al. 2014) and other newts (see e.g., Wood and Goodwin 1954; Kaplan and
Sherman 1980). Dasgupta (1996) and Lucy et al. (2014) only found newt eggs in the stomach contents of females and denoted that the Himalayan newt oophagy is sexspecific. Sex-specific oophagy has also been reported in other newt species such as Taricha torosa (Marshall et al. 1990). However, Phimmachak et al. (2015) did not observe conspecific oophagy in $T$. podichthys from Laos. In our work, T. uyenoi shows the oophagy in the adult male as part of egg material was found in the fecal pellet. Contrast to Dasgupta (1996) that found only female T. verrucosus (Darjeeling, India) cannibalized eggs. In our study, males of $T$. uyenoi consumed more diverse prey than those of females. During breeding period, the diets of adult males and females T. verrucosus comprised both aquatic and terrestrial elements. The males consumed more diets than females during the post-breeding period while the female consumed more during the breeding period. However, Phimmachak et al. (2015) found the diet composition, number of prey consumed, and volume of prey consumed did not differ among adult males and females. 

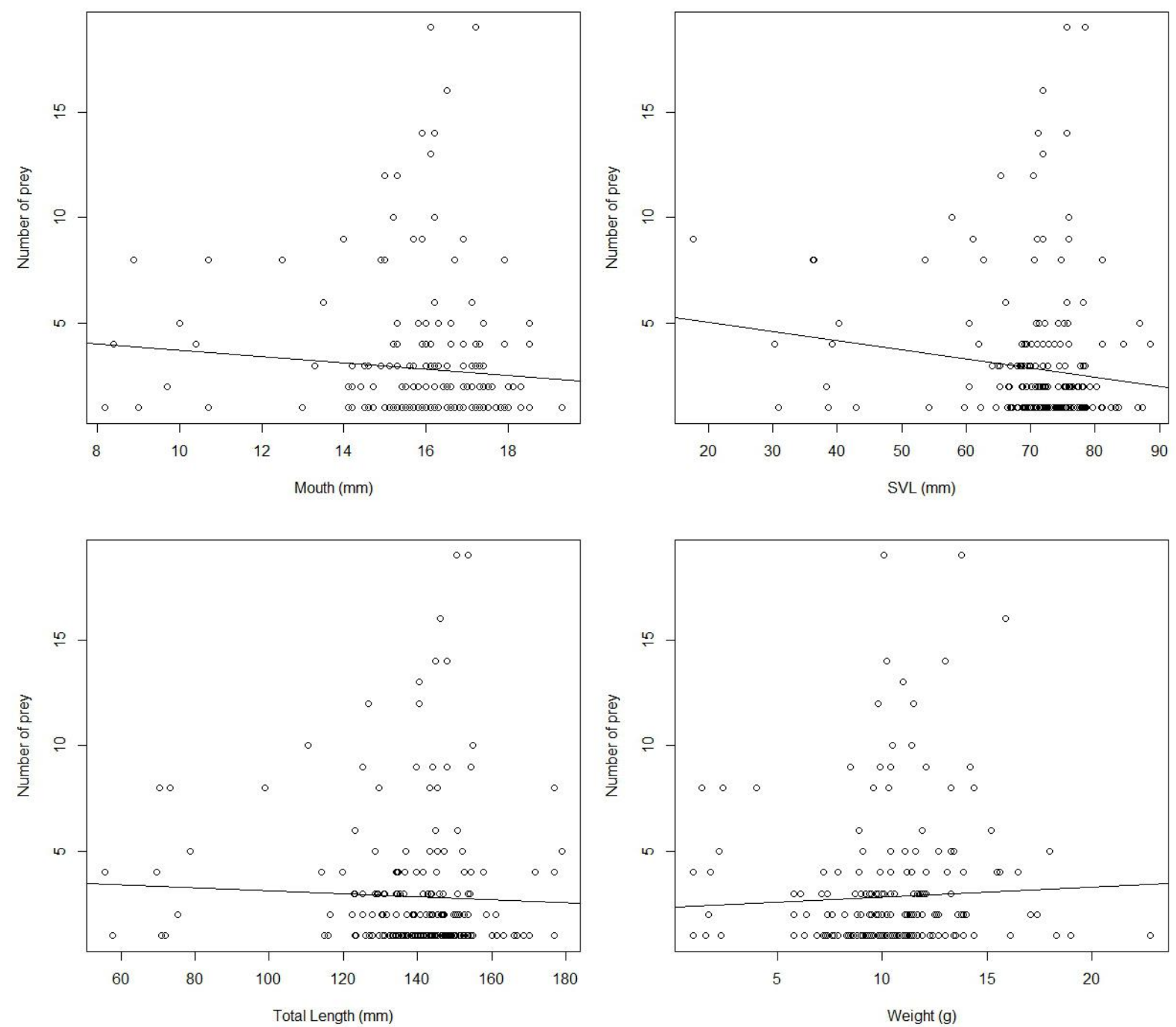

Figure 4. The Spearman rank coefficient (95\% confidence interval test) comparison of number of prey individuals versus mouth, SVL, weight, and total length. A. prey volume versus mouth, B. prey volume versus SVL, C. prey volume versus weight, D. prey volume versus total length. Number of prey individuals and SVL had a significant negative correlation $(p<0.05)$.

The Phuping newt appears to be a generalist predator rather than a specialist. The most important food was arthropods as similar to those of previous works investigated on amphibians from Thailand (see e.g., Chuaynkern et al. 2009; Ponpituk 2014; Thongproh et al. 2019). There are five most important groups represented in the diet of the Phuping newt: Formicidae (ants), Lymnaeidae (pond snails), unknown snails, Blattidae (cockroach), and Paradoxosomatidae (flat-backed millipedes). However, there are many ways to assess animal diets. With the observational method (e.g., Kaplan and Sherman 1980) the researcher directly observes the food eaten by the animal. With the fecal pellet analysis method (e.g., Chuaynkern et al. 2009; Thongproh et al. 2019), feces are collected from the animals and the remaining part of food from digestion is identified. The stomach-flushing method (e.g., Dasgupta 1996; Lucy et al. 2014; Wu et al. 2007; Phimmachak et al. 2015), collects food by flushing their stomachs. With the stomachdissecting method (Wu et al. 2007), the animal is killed and its stomach is cut and take off. As T. uyenoi is listed as protected animal by Thai law (Ministry of Natural Resources and Environmental 2017) and investigation on dietary is required numerous individuals, therefore the fecal pellet analysis is appropriated and selected for our study method. However, the observational method and fecal pellet analysis may be received the exactly consumed preys because the methods are difficult and the prey items might be completely digested or unrecognizable. Our previous work based on fecal pellet analysis evidenced good recognizable prey items (Chuaynkern et al. 2009; Ponpituk 2014; Dowwiangkan et al. 2016). 


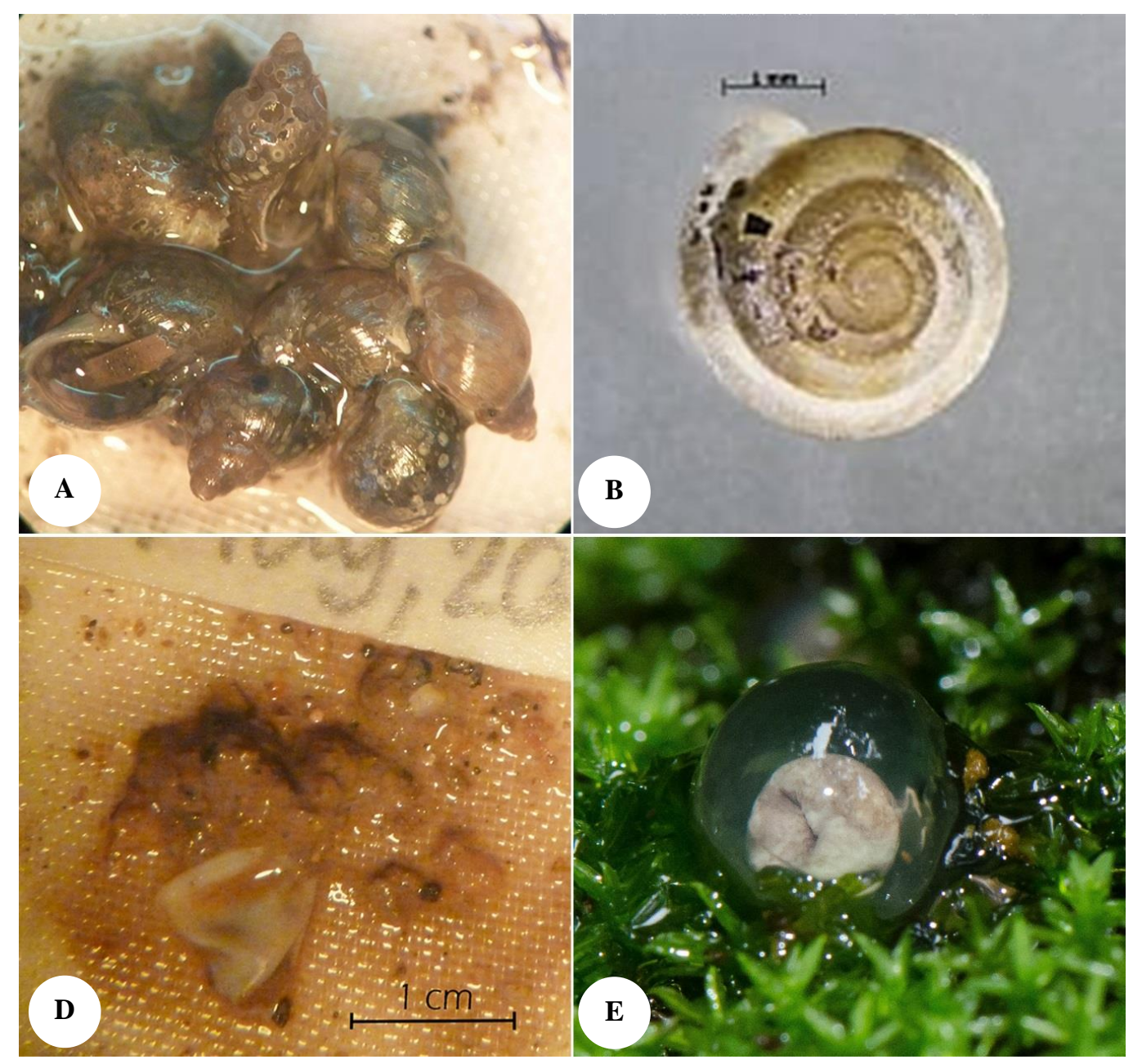

Figure 5. Selective food items observed in the Uyenoi' newt. A. Snail species 1, B. Snail species 2, C. Unhatched egg of the Phuping newt obtained from the fecal pellet, D. Unhatched egg of the Phuping newt from oviposition

However, the main problem with the fecal pellet analysis might be completely digested prey. Dowwiangkan et al. (2016) and the present work did not find earthworms in the fecal pellets of $T$. uyenoi whereas earthworms were found in the diet of other newts based on the flushing technique: T. verrucosus (Dasgupta 1996; Lucy et al. 2014) or T. podichthys (Phimmachak et al. 2015). Therefore, $T$. uyenoi might eat earthworms, but the prey may have been completely digested before production of a fecal pellet and could not be observed. According to Solé et al. (2005), the stomach-flushing method is useful for dietary analyses of protected species or populations under long term study as it was claimed that the method does not require killing the animals to obtain dietary data. However, Joly (1987) showed that treatment can sometimes cause mortality.

The ecological niche of the prey categories found in the pellet indicates that the Phuping newts search for their food mainly on the ground $(91.22 \%)$ rather than in water (8.77\%). This is not congruent with $T$. verrucosus from Darjeeling Himalayas (India) in which these ratios are equal (Dasgupta 1996). However, the diet of studied newts consistently comprised both terrestrial and aquatic prey as presented in Lucy et al. (2014), Phimmachak et al. (2015), and Dowwiangkan et al. (2016).

Today, we are in a worldwide situation in which many animals face declining numbers. Therefore, killing newts for dietary study or other disciplines is even less justified. Improved techniques are recommended to avoid killing of numerous animals for nutritional studies, in particular, because of the worldwide threat to amphibian populations.

\section{ACKNOWLEDGEMENTS}

We would like to thank our institutions (Kasetsart University and Khon Kaen University, Thailand) for supporting this study in various ways. This research is supported by the Graduate Program Scholarship from The Graduate School, Kasetsart University, Thailand. For assistance during the field surveys, our thanks go to Niwat Intawin, a staff member of the HKM, Ms. Mayuree Umponjan, Apinya Saisamorn, a staff member of WCS, and all of the forest biology cottage family. We also would like to thank the National Research Council of Thailand (Project: Biodiversity Monitoring on the Climate Changes in Huai Kogma Biosphere Reserve and adjacent area of 
Doi Suthep-Pui Mountain Ecosystems, Chiang Mai Province, Indonesia) and the International Affairs Division (Khon Kaen University) for supported study area and funding source.

\section{REFERENCES}

Bickford D, Howard SD, Ng DJJ, Sheridan JA. 2010. Impacts of climate change on the amphibians and reptiles of Southeast Asia. Biodivers Conserv 19: 1043-1062.

Chuaynkern Y, Duengkae P. 2014. Decline of amphibians in Thailand. In: Heatwole H, Das I (eds.) Conservation Biology of Amphibians of Asia: Status of Conservation and Decline of Amphibians in Eastern Hemisphere. Natural History Publications, Borneo.

Chuaynkern Y, Wongwai A, Duengkae P, Hasin S. 2009. Kalophrynus interlineatus (Striped Sticky frog): Diet. Herpetol Rev 40(2): 205

Chuensri C. 1974. Freshwater crabs of Thailand. J Fish Environ 7: 12-40.

Devi NT. 2005. The food of the Himalayan newt Tylototriton verrucosus (Anderson): A preliminary study. J Bombay Nat Hist Soc 102: 166 168.

Dowwiangkan T, Ponpituk Y, Chuaynkern Y, Duengkae P. 2016. Diet of Himalayan newt (Tylototriton uyenoi) in Chiang Mai Province. Proceedings of Thai Forestry Conference. Kasetsart University, Bangkok, 1-4 May 2016. [Thai]

Dowwiangkan T, Ponpituk Y, Chuaynkern C, Chuaynkern Y, Duengkae P. 2018. Population and habitat selection of the Tylototriton uyenoi in the Maesa-Kogma Biosphere Reserve, Chiang Mai Province, northern Thailand. Alytes 36: 300-313.

Duellman WE, Trueb L. 1994. Biology of Amphibians. 2nd ed. The John Hopkins University Press, Baltimore.

Dusgupta R. 1996. Feeding ecology of the adult Himalayan salamander Tylototriton verrucosus Anderson, 1871 (Caudata: Salamandridae). Herpetozoa 9: 19-29.

Frost DR. 2020. Amphibian species of the world: An online reference. https://amphibiansoftheworld.amnh.org/index.php.

Griffiths RA. 1986. Feeding niche overlap and food selection in smooth and palmate newts, Triturus vulgaris and T. helveticus, at a pond in Mid-Wales. J Anim Ecol 55: 201-214.

Hernandez A. 2016. Crocodile newts: The genera Tylototriton and Echinotriton. Edition Chimaira, Frankfurt am Main.

Hernandez A. 2017. New localities for Tylototriton panhai and Tylototriton uyenoi Nishikawa, Khonsue, Pomchot \& Matsui 2013 in Northern Thailand. Bulletin de la Société Herpétologique de France 162: 110-112.

Hernandez A, Escoriza D, Pomchote P, Hou M. 2019. New localities for Tylototriton uyenoi, T. panhai and T. anguliceps in Thailand with remarks on the southernmost distribution of the genus. Herpetol Bull 147: $15-18$.

Inmadon R, Tanamai S, Dumrongrojwattana P. 2011. Species and habitats of mollusk in Sakeao Province. In: Proceedings of 49th Kasetsart University Annual Conference: Science, 1-4 February 2011, Bangkok.

Joly P. 1987. Le régime alimentaire des amphibiens: Méthodes d'etudes. Alytes 6: 11-17.

Kaplan RH, Sherman PW. 1980. Intraspecific oophagy in California newts. J Herpetol 14: 183-185.

Kuzmin SL, Dasgupta R, Smirina ÉM. 1994. Ecology of the Himalayan newt (Tylototriton verrucosus) in Darjeeling Himalayas, India. Russian J Herpetol 1: 69-76.

Le DTT, Rowley JJL, Tran DTA, Vo TN, Hoang HD. 2018. Diet composition and overlap in a montane frog community in Vietnam. Herpetol Conserv Biol 13: 205-215.

Lucy H, Lal P, Yenisetti SC. 2014. Food and feeding patterns of the Himalayan newt, Tylototriton verrucosus Anderson in Senapati District, Manipur. Modern J Life Sci 13: 1-7.
Lunghi E, Bruni G, Manenti R, Ficetola GF. 2014. Use of visible implant elastomer on two amphibians orders (Anura and Caudata): Data on efficiency and reliability. In: Atti X Congresso Nazionale Societas Herpetologica Italica, 15-18 October 2014, Genova.

Marod D, Kutintara U. 2009. Forest Ecology. Kasetsart University, Bangkok. [Thai]

Marshall CJ, Doyale LS, Kaplan RH. 1990. Intraspecific and sex-specific oophagy in a salamander and frog: Reproductive convergence of Taricha torosa and Bombina orientalis. Herpetologica 64: 395-399.

Ministry of Natural Resources and Environment. 2017. Notification of the Ministry of Natural Resources and Environment. No. 134 B.E. 2560, 12 April 2017.

Monzon RB, Kitikoon V, Thammapalerd N, Temcharoen P, Sornmani S, Viyanant V. 1993. Comparative shell morphology of Lymnaea (Bullastra) cumingiana (Pulmonata: Lymnaeidae) and related taxa in the Indo-Pacific Region. SE Asian J Trop Med Public Health 24: 554562.

Naiyanetr P. 1997. Dromothelphusa sangwan n. sp., a new freshwater crab from Thailand (Decapoda, Brachyura, Potamidae). Crustaceana 70: 385-393.

Nishikawa K, Khonsue W, Pomchote P, Matsui M. 2013. Two new species of Tylototriton from Thailand (Amphibia: Urodela: Salamandridae). Zootaxa 3737: 261-279.

Oliveira F, Erzini K, Gonçalves JMS. 2007. Feeding habits of the deepsnouted pipefish Syngnathus typhle in a temperate coastal lagoon. Estuar Coast Shelf Sci 72: 337-347.

Pattanavibool A, Dearden P. 2002. Fragmentation and wildlife in montane evergreen forests, northern Thailand. Biol Conserv 107: 155-164.

Phimmachak S, Stuart BL, Aowphol A. 2015. Ecology and natural history of the knobby newt Tylototriton podichthys (Caudata: Salamandridae) in Laos. Raffles Bull Zool 63: 389-400.

Pinkas L, Oliphant MS, Iverson ILK. 1971. Food habits of albacore, Bluefin Tuna, and Bonito in California waters. Fish Bull 152: 1-105.

Pomchote P, Pariyanonth P, Khonsue W. 2008. Two distinctive color patterns of the Himalayan newt Tylototriton verrucosus (Urodela: Salamandridae) found in Thailand and its implication on geographic segregation. Nat Hist J Chulalongkorn Univ 8: 35-43.

Ponpituk Y. 2014. Diet of Amphibians in Hill Evergreen Forest at Doi Suthep-Pui National Park, Chiang Mai Province. [Thesis]. Kasetsart University, Bangkok. [Thai]

Qian L, Sun X, Li J, Guo W, Pan T, Kang X, Wang H, Jiang J, Wu J, Zhang B. 2017. A new species of the genus Tylototriton (Amphibia: Urodela: Salamandridae) from the southern Dabie mountains in Anhui Province. Asian Herpetol Res 8: 151-164.

Rowley JJL, Shepherd CR, Stuart BL, Nguyen TQ, Hoang HD, Cutajar TP, Wogan GOU, Phimmachak S. 2016. Estimating the global trade in Southeast Asian newt. Biol Conserv 199: 96-100.

Shen Y, Jiang J, Mo X. 2012. A new species of the genus Tylototriton (Amphibia, Salamandridae) from Hunan, China. Asian Herpetol Res 3: $21-30$.

Solé M, Beckmann O, Pelz B, Kwet A, Engels W. 2005. Stomach-flushing for diet analysis in anurans: an improved protocol evaluated in a case study in Araucaria forests, southern Brazil. Stud Neotrop Fauna E 40: 23-28.

Thongproh P, Duengkae P, Ratree P, Phetcharat E, Kingwongsa W, Jaitrong W, Chuaynkern Y, Chuaynkern C. 2019. Species diversity and prey items of amphibians in Yoddom Wildlife Sanctuary, northeastern Thailand. Biodiversitas 20: 1718-1732.

Triplehorn CA, Johnson N. 2005. The study of Insects. CA, United States of America.

Wood JT, Goodwin OK. 1954. Observations on the abundance, food, and feeding behaviour of the newt, Notophthalmus viridescens viridescens (Rafinesque), in Virginia. J Elisha Mitchell Sci Soc 70: 27-30.

Woodcock BA. 2005. Pitfall trapping in ecological studies. In: Leather SR (eds.) Insect Sampling in Forest Ecosystems. Blackwell Publishing, Oxford.

Wu ZJ, Li YM, Wang YP. 2007. A comparison of stomach flush and stomach dissection in diet analysis of four frog species. Acta Zool Sin 53: 364-372. 